\title{
A COMPOUND LAMS-MOODLE ENVIRONMENT TO SUPPORT COLLABORATIVE PROJECT-BASED LEARNING: A CASE STUDY WITH THE GROUP INVESTIGATION METHOD
}

\author{
Giorgos PASCHALIS \\ Department of Electrical and Computer Engineering \\ University of Patras \\ Patras, Greece
}

\begin{abstract}
Collaborative project-based learning is well established as a component of several courses in higher education, since it seems to motivate students and make them active in the learning process. Collaborative Project-Based Learning methods are demanded so that tutors become able to intervene and guide the students in flexible ways: by encouraging them to develop independent solutions and also by keeping their efforts and activities targeted towards the lesson goals. Students, on the other hand, need to develop important skills in searching and analyzing information as well as in communication and time management. In this paper, we propose the design of a collaboration script, following the "Group Investigation method", to support the tutors and students of a collaborative project-based course on 'DataBases'. We implemented this script using a compound e-learning collaborative environment based on MOODLE and LAMS, which have provided tutors with several tools and methods to involve in the learning process. The evaluation of the students' projects and the comparison with the corresponding projects of the previous academic year showed a better level of collaboration and performance of the students but also proved that the learning environment offered the tutors a more efficient way to guide their students in Collaborative Project-Based Learning.
\end{abstract}

Keywords: Collaborative project-based learning, collaboration script, group investigation method, LAMS, Moodle.

\section{INTRODUCTION}

Many tutors/educators, as a part of their courses within an academic semester, assign individual or group projects to their students. These projects - depending on the nature of the course - are usually complicated enough and require continuous support from tutors (Donnelly \& Fitzmaurice; 2005).

Project-Based Learning (PBL) is an instructional (and curricular) learner-centered approach that empowers learners to conduct research, integrate theory and practice and apply knowledge and skills to develop a viable solution to a defined problem (Savery, 2015). It is an individual or group activity that goes on over a period of time, resulting in a product, presentation, or performance. It typically has a timeline and milestones, and other aspects of formative evaluation as the project proceeds.

Collaborative learning $(\mathrm{CL})$ approaches seem to promote learning through the interactive engagement of students in activities, while at the same time getting them involved in a social learning experience. There has been evidence (Johnson \& Johnson, 1998; Hake, 1998; Vogiatzaki \& Avouris, 2010, Avouris et al, 2010) that such approaches have a positive effect on the learning outcome. In particular, Hake has reported the results of a wide-scale survey study that involved pre- and post-test data from first year courses in Physics. This survey involved over 6,000 students in the US. He compared performance in 
this test of students of traditional and active engagement courses. The results of this large-scale study show a great advantage of the interactive engagement and, in particular, of the collaborative learning approach.

Free collaboration, with its unstructured interactions, does not necessarily by itself produce the interactions we want so as to promote learning. One way to enhance the effectiveness of collaborative learning is to structure interactions by engaging students in well-defined scripts of action. Technology - via the continuously expanding Learning Management Systems (LMSs) - offers the ability integrating new information and communication tools (e.g. multimedia, simulations, external representations, group awareness widgets and coordination tools) as useful for enhancing cognitive performance (Thompson, McGill, 2014).

LMSs like Moodle, LAMS, Blackboard, Collage, Sakai, etc. are online collaboration platforms that integrate a range of internet-based tools that allow learners to do things together online. This may include online conversations in forums and email lists, the cocreation of documents on wikis, file sharing and storing, etc. Such tools provide a range of services for designing, managing and delivering online collaborative learning activities in addition to authoring environments for creating sequences of learning activities. Most of the LMSs provide a lot of collaboration and communication tools to support information sharing and communication among learners in a course and, through these, enable collaborative learning. Some of them support unstructured collaboration spaces that group course participants exploit and offer an open interface for communication and sharing of knowledge and experiences (Talavera \& Gaudioso, 2004).

A script is a sequence of phases and each phase can be described by attributes (Dillenbourg, 2002). A collaboration script is a set of instructions prescribing how students should form groups, how they should interact and collaborate and how they should solve the problem at hand. The need for using scripts emerges from the fact that collaborative learning is a complex process where it is very difficult - if not impossible for the instructor to consider all interacting parameters in order to foster productive learning experiences (Dillenbourg et al, 1995). Instead, it is suggested that the instructor guides the learners' interactions within the group by implementing an appropriate structure (O'Donnell et al, 1992). In this way, the probability of productive student-tostudent and student-to-teacher learning interactions is increased. Scripting collaborative learning has commonly been reported to result in improved learning outcomes (HertzLazarowitz \& Miller, 1992; Weinberger et al, 2002; Kollar et al, 2005; Rummel \& Spada, 2007).

Scaffolding collaboration can increase the probability of successful learning outcomes (Fischer et all; 2007). CSCL scripts embedded in (Dillenbourg \& Jermann, 2007), or interpreted by (Hernandez-Leo et al., 2006c) e-learning environments aim to shape the way learners interact with each other to elicit fruitful interactions. The design of effective scripts is a non-trivial task that requires significant expertise in, and knowledge of, the possibilities and risks of structuring collaboration (Fischer et al., 2007).

Recent approaches (such as the design studio by Mor \& Mogilevsky, 2013) consider the value and benefits (if not the inevitability) of using and combining multiple tools and design representations (Conole, 2008) for the elaboration of complex learning activities, such as projects in academic courses.

Students of the Computer Science Sector of the Department of Electrical and Computer Engineering of the University of Patras, Greece, attend, in the 8th semester as part of their undergraduate studies, the elective Course "Databases". The course includes both theory and lab sessions for engaging the students in "hands on" work. The course traditionally involved lectures on ERD designing, database schema designing and managing using SQL. Since the academic year 2005-2006, in order to encourage more 
active student participation, tutors have been giving students collaborative projects on different subjects. The way they have worked all these years has been as follows: Students would choose a partner among their fellow students and a project subject among 15-20 possible projects subjects. Then, they would collaborate for a six-week period in order to create the requested deliverables which are: a Report with database ERD, SQL code of tables and queries, an application to run a database through it and the application User Manual. Students would use a Moodle environment as their usual LMS to work and case specific tools to handle the database. If the students of any group had questions about the project, they had to contact the course tutors to help them. In the final week of the semester, an oral presentation of all projects was organized.

From our teaching experience in previous academic years, and pre-mentioned work, we verified the necessity for structuring the learning and collaborative process more in order to help students achieve better learning results and tutors supervise the learning process more efficiently. For these reasons, we diagnosed the need for a collaborative learning environment, which would have characteristics and capabilities that support students and tutors. For students, the compound learning environment must: a) divide whole tasks in sub-tasks, b) manage their available time for each sub-task better, c) help them to finish all sub-tasks that have to be completed, d) scaffold their collaboration through synchronous and asynchronous communication tools or shared workspaces. Also, it would provide tutors with some capabilities like: a) monitoring and evaluating the cognitive process employed by the students, b) supervising students' collaboration in order to improve it, c) guiding and prompting the students synchronously or asynchronously.

In this general frame, we deemed it appropriate to use a compound collaborative environment consisting of Moodle, LAMS and other specific to the case tools to offer students and their tutors some of the pre-described capabilities. The experience of organizing, supporting and evaluating student projects during the last academic year 2012-13 and comparing student project grades with the previous year's ones, is the focus of this paper. The created collaboration environment enabled us to investigate whether Scripted Collaborative Learning would lead students to better cognitive results. Also, we were able to see the advantages and weaknesses of each of the used LMSs and discover if their integration covers one another's weaknesses. The rest of the paper is organized as following: Section II refers to the related literature, Section III describes the method used on the compound LAMS-Moodle environment, section IV the design of the script and the methodology and section $V$ discusses the results of the whole experience for both students and their tutors.

\section{RELATED LITERATURE}

Jarvela et al. (2015) give an illustrative example using technological tools to support that successful collaboration in CSCL contexts requires targeted support for promoting individual self-regulatory skills and strategies, peer support, facilitation of self-regulatory competence within the group.

The Prieto et al. (2014) study suggests that there is no single "silver bullet" tool for editing learning designs or CSCL and that teachers appreciate different kinds of support, depending on the moment and the concrete task at hand. Their data also suggests that learning design and CSCL script tool designers should not neglect other features that are not necessarily related with the act of designing itself. Such features include the connection of the tool with the teachers' learning platform of choice, the cost of integrating the tool into the existing workflow/practice, with its different restrictions (and which may even be variable with time).

Carlos Alario-Hoyos et al. (2014) present GLUE! and GLUE!-PS, two alternative routes for the deployment of collaborative learning situations that respectively tackle the integration of multiple external tools in multiple Virtual Learning Environments (VLES), 
and the deployment of abstract learning designs generated within multiple authoring tools in multiple VLEs. To support their tool, they show an authentic CSCL situation, in which an academic course teacher who uses Moodle, needs drawing tools and collaborative text editors with more features than Moodle built-in tools have.

Ernie Ghiglione et al. (2009) show how using the LAMS Tool Contract provides a flexible architecture to incorporate learning activities to create elaborate learning designs using LAMS' highly visual environments.

Bower \& Wittmann (2009) gauged the perceptions of sixty-eight teacher education students of each of these systems as frameworks for designing learning experiences. Their responses indicated that the majority of students appreciated that different tools were suitable for different purposes.

Masterman et al. (2009) investigate experienced teachers' initial perceptions of learning design as a conceptual framework for practice through its instantiation in either LAMSv2 or Moodle. In this study, the participants' perceptions of 'learning design' as a practice were examined based on experience designing in one or other of the tools, with a general consensus that such approaches were useful for structuring learning, catering to a range of abilities and motivating students.

Walker and Masterman (2006) have examined the issue of learning design reusability based on participants' use of either LAMS or Moodle, with attitudes towards reuse being more favorable than the extent to which designs were reused in practice.

The final report of the ALeD (Authoring Using Learning Design) project (Joint Information Systems Committee, 2007) concluded that LAMS and Moodle were both effective for designing and facilitating online learning where there is a strong emphasis on sharing, collaboration and reflection. However, all the aforementioned studies compared tools to each other, and no one reports on the benefits of their integrated use.

\section{THE COMPOUND ENVIRONMENT AND METHOD}

In order to achieve the objectives discussed in the introduction section, during the academic year 2012-13, we created a collaboration environment using Moodle, LAMS and application-specific external tools in the course site. In this way: a) students did not change their familiar Moodle environment, in which they had been doing their laboratory exercises; b) the LAMS environment gave us the ability to structure the whole process better, organizing the phases, and giving students the necessary directions and tools they needed. Also, via the LAMS Monitor environment, we could watch student progress in each phase and give suitable help when asked; c) if there were some questions from two or more students/student groups, we could upload general directions for them through the Moodle environment; d) LAMS provided students with the ability to use external tools, when its toolbar couldn't support task-specific activities (e.g. create UML flowcharts, ERDs, SQL tables and queries) necessary to design, create and manage a database.

\section{LAMS}

The Learning Activity Management System (LAMS -http://www.lamsfoundation.org/) is an e-learning system for authoring, managing and delivering online collaborative learning activities. It has the power to present in a complete and functional way different activity structuring techniques. It provides the appropriate support to develop a collaboration approach through shared workspaces, wiki editing, Q\&A, multiple choice, voting activities and other synchronous and asynchronous communication tools, such as forums and chat rooms, where group members can exchange ideas while providing an open-source platform for designing, managing and delivering online learning sequences (LAMS International, 2009). It also includes a range of pre-installed plugins for webconferencing, mapping exercises, image creation, spreadsheet tasks and more, which enable students to integrate a variety of new activities into their learning designs. These features allow LAMS to be effectively used to develop pre-service teachers' learning 
design skills (Bower, 2008; Cameron, 2006, 2007; Kearney \& Cameron, 2008). However, LAMS is not appropriate for sharing general directions to all project groups simultaneously.

\section{MOODLE}

The Modular Object-Oriented Dynamic Learning Environment (Moodle http://moodle.org/) is a free source Learning Management System (LMS) with millions of users and courses around the world and, like LAMS, it also offers the ability to create chats, forums, wikis, online quizzes and disseminate resources. It does not come with the same range of pre-installed plugins as LAMS; however, it does have a strong development community offering hundred modules and plugins that can be installed at the administrator's discretion. Its main use is to present in the same environment all course materials ordered in units and ready for consultation with students (Dougiamas \& Taylor, 2003). Nonetheless, the Moodle environment does not have the necessary tools to set the specific order/flow in which students complete the activities. Consequently, it is not recommended as reliable support for scripted learning.

\section{The Group Investigation Collaboration Method}

For the implementation of the proposed collaborating Environment, the Group Investigation Collaboration method (Sharan, S., \& Hertz-Lazarowitz, R., 1980; Sharan Y., \& Sharan, S., 1994) was used. We selected this collaboration method because, according to Sharan (Sharan, 1980; Tan, 2006), it is appropriate for Problem-Based Learning. Students form interest groups, within which they plan and conduct an investigation, and synthesize their findings into a group presentation for the class. The teacher's general role is to make the students aware of resources that may be helpful while carrying out the investigation.

It is based on the four main elements of the learning process, namely: 1) Investigation, 2) Interaction, 3) Interpretation, 4) Intrinsic motivation. During the employment of this method, groups work on similar problems using versatile approaches. The whole process leads to the active construction of knowledge.

In a Group Investigation context, student groups plan, conduct, and report on in-depth research projects. These projects provide opportunities for students to study a topic extensively and gain specialized knowledge about a specific area. Allowing students to select topics of special significance to them, to form interest groups and to carry out their own research can be very motivating. This method also helps students recognize that research does not always follow the same series of steps but is, instead, contextdependent. Students learn that good research is a logical, well-organized endeavor that differs from one discipline to another, from one project to another, and even from one researcher to another. When students complete a Group Investigation, they enhance their understanding of the importance of discovery. When they participate in peer and teacher review of their projects, they gain practical experience in both giving and receiving constructive criticism. Finally, because, in conducting the investigation, the group follows a series of steps and is working within a time frame, it discourages plagiarism, a phenomenon sometimes associated with conventional term paper assignment.

\section{METHODOLOGY}

\section{Project Preparation and Execution}

First, the tutors in the course announced 15 possible project themes in the Moodle Environment. The projects were optional and they contributed by $20 \%$ to the total grade of the course. Some typical examples of projects undertaken were: Hospital, Supermarket, Music Library, etc. One theme was open, so students could suggest the project theme they wanted.

The students had 5 days to choose a partner on their own as well as a project. We selected this group formation method because self-selected groups seem to work best in 
small classes, who already know each other, especially when the collaboration time is not very long (Walvoord, 1986).

Then, the project problems were allocated to the groups and detailed instructions about projects and the way that they would be graded were given. Finally, 20 from a total of 37 students in the course took on projects. 16 students formed 8 pairs, while 4 students did their projects individually.

\section{The Activity Flow of the Course}

The proposed learning flow for the course consisted of four separate phases of computermediated collaborative problem-solving activities (table 1), irrespective of whether students worked in pairs or not. Each phase was organized according to the previously mentioned Group Investigation Collaboration method. As the underlying strategy is Project-Based Learning, the overall structure leads user activities to a global goal, which consists of individual phases and sub-tasks that are carried out using several tools of LAMS and external tools, when needed.

This activity had the objective of stimulating the students to work as a group for a considerable amount of time, of compelling them to get involved in organizing their activities and making optimal use of the available tools and resources, and of giving to the students the opportunity to deal with a complex problem that required much more advanced programming skills and knowledge than that introduced in the frame of the course.

Table 1. The 4 Phases of the Collaboration Script.

\begin{tabular}{llll}
\hline PHASES & Learning Objects & Tools & Deliverables \\
\hline Phase A & $\begin{array}{l}\text { ERD } \\
\text { Logical diagram }\end{array}$ & $\begin{array}{l}\text { Chat } \\
\text { Forum } \\
\text { Wiki } \\
\text { Synergo } \\
\text { DBDesigner }\end{array}$ & $\begin{array}{l}\text { Report } \\
\text { ERD (.synergo) } \\
\text { Logical diagram } \\
\text { (.xml) }\end{array}$ \\
Phase B & $\begin{array}{l}\text { SQL tables and } \\
\text { queries }\end{array}$ & phpMyAdmin & $\begin{array}{l}\text { Report } \\
\text { SQL }\end{array}$ \\
Phase C & $\begin{array}{l}\text { Application } \\
\text { Interface }\end{array}$ & PHP or Java & Application \\
Phase D & $\begin{array}{l}\text { Testing \& } \\
\text { Documentation }\end{array}$ & & Manual \\
\hline
\end{tabular}

The learning design of the course, according to the structure introduced in table 1, was implemented in LAMS, where we defined the tasks and the scheduling of the whole activity (Figure 1). The students, after the general directions that were given by their tutors, downloaded their project and began to work in four phases. Each phase was organized according to the Group Investigation method. Firstly, with a noticeboard LAMS tool, we gave specific directions to the students about what to do in each phase. In phase A, we additionally used a Mindmap LAMS tool to allow students to organize their concepts and ideas about the project theme. With the Chat, Forum and Wiki LAMS tools, we gave them the ability to collaborate with each other synchronously or asynchronously. If there were questions that could not be answered by the other member of the group, or if there were questions from students who worked individually, we could check them via the LAMS monitor environment, and give the requested help. When a similar question was 
asked by more than one group/individual, we would upload the answer in the Moodle Environment, so that all students could see it. Finally, with the Submit Files LAMS tool, each group's members/individual could upload each phase deliverable.

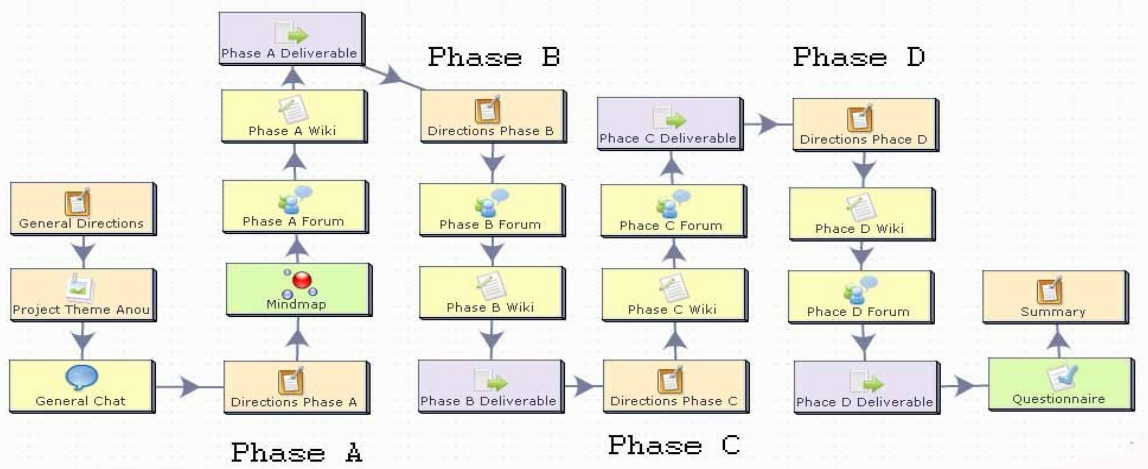

Figure 1. LAMS sequences in which the 4 different phases are obvious, each one designed according to the group investigation method.

Students had a six-week period for project work. With the LAMS monitor environment, we watched each group's/individual's progress in the LAMS sequence in order to offer appropriate help when asked. If someone delayed in an activity, we motivated him by giving the help needed for them to overcome any difficulties. Also, we kept a diary of the process in which we noted the detailed student activities, the time each one took to complete them and the kind of help we offered. This helped us to present our learning experience as described in the Results Section which follows.

After the end of the fourth phase, we gave students via the Survey LAMS tool an evaluation questionnaire for them to describe their whole experience. With this, we wanted to analytically explore the participants' experience and their personal beliefs about the proposed collaborative method and the supporting environment. The questionnaire had been authored following a multi-faceted approach, combining qualitative and quantitative data, and was constructed taking into consideration theoretical assumptions of multiple literature perspectives (Gillham, 2000; Oppenheim, 1992; Sapsford, 1999), in order to clarify certain goals. Qualitative data were recorded through follow-up observation data during the whole procedure and individual face-toface conversations with some students who were randomly selected.

\section{RESULTS}

The students delivered their reports using the Submit Files LAMS tool, which is the last tool of each phase. Two students asked for three days extra time from the set project deadline, which was granted to them. In the final week of the semester, an oral presentation of all projects was organized. The students' final grades, for those who worked in groups, were based by $\mathbf{8 0} \%$ on the quality of the given solution and by $20 \%$ on the collaboration through the compound environment. We applied this grading method so as to motivate the students to use our proposed script. 
The results were very encouraging. All group members/individuals ran almost all activities in their LAMS sequences and they had active participation, which helped them to elaborate on their projects.

As we can observe in Table 2, where we compare student grades in projects in the Academic years of 2011-12 and 2012-13, their mean grades increased significantly (mean difference 1.17). We think this happened due to the following: a) the whole project was split in 4 sections (phases), with specific instructions about each section's deliverable; b) all students could estimate better the whole time that was required for each section and schedule work according to their available time; c) the students had a supporting environment with synchronous and asynchronous activities, which gave them the ability to interact with each other and with their tutors. In this way, they could have their questions answered with less effort and more quickly than in the previous year. Also, we can see in Table 2 that Standard Deviation decreased considerably (Standard deviation difference=0.5). A possible interpretation for this finding is that the compound environment and the followed collaborative method helped weaker students to improve their knowledge and, consequently, their grades.

Table 2. Students' Project grades comparison.

\begin{tabular}{lccc}
\hline Academic Year & $\begin{array}{c}\text { Number of } \\
\text { Students }\end{array}$ & $\begin{array}{c}\text { Mean (1-10 } \\
\text { scale) }\end{array}$ & Std. Deviation \\
\hline $2011-12$ & 16 & 7.87 & 1.63 \\
\hline $2012-13$ & 20 & 8.70 & 1.13 \\
\hline
\end{tabular}

In table 3, we compare the grades of the students who worked in groups with those of the students who worked individually. However, because of the rather small number of students who worked individually, we cannot reach safe conclusions.

Table 3. Students' Project grades comparison 2012-13.

\begin{tabular}{lccc}
\hline Students & $\begin{array}{c}\text { Number of } \\
\text { Students }\end{array}$ & $\begin{array}{c}\text { Mean (1-10 } \\
\text { scale) }\end{array}$ & Std. Deviation \\
\hline Worked in groups & 16 & 8.90 & 0.83 \\
\hline Worked individually & 4 & 8.00 & 1.73 \\
\hline
\end{tabular}

All the students who took part in the projects completed our evaluation questionnaire. 18 were male and 2 female. All of them had been taught programming languages during their previous years of studies with most programming skills related to $C_{\text {, Java and }}$ JavaScript. Regarding their acquaintance with the course subject, most of them had no previous experience with designing, implementing and handling databases. $40 \%$ had not used any Database Management System before, 20\% had used Microsoft Access, 20\% Mysql and $15 \%$ SQL Server and 5\% other. Student answers to our questions are shown in the following Table 4.

In the question of what they had liked more about the compound environment as concerns the collaboration between them and their tutors, the students answered: the ability for very constructive and direct help with the questions during the project, the step-by-step guidance during all phases that did not allow room for misunderstandings, the wiki LAMS tool, which allowed students/tutors to make collaborative edits to the content provided, and the forum LAMS tool, with which they could post their questions and receive answers from their partners/tutors. 
Table 4. Student answers to our questionnaire.

\begin{tabular}{|c|c|c|c|c|}
\hline \multicolumn{5}{|c|}{ Which do you prefer more, collaborative or individual projects? } \\
\hline \multicolumn{3}{|c|}{$\begin{array}{l}\text { Collaborative } \\
\quad 65 \%\end{array}$} & \multicolumn{2}{|c|}{$\begin{array}{l}\text { Individual } \\
\quad 35 \%\end{array}$} \\
\hline \multicolumn{5}{|c|}{ How satisfied are you with the help offered by your partner? } \\
\hline $\begin{array}{l}\text { Very satisfied } \\
90 \%\end{array}$ & $\begin{array}{l}\text { Satisfied } \\
10 \%\end{array}$ & $\begin{array}{c}\text { Neutral } \\
\mathbf{0 \%}\end{array}$ & $\begin{array}{l}\text { Dissatisfied } \\
0 \%\end{array}$ & $\begin{array}{l}\text { Very Dissatisfied } \\
0 \%\end{array}$ \\
\hline \multicolumn{5}{|c|}{ Did you ask for help from your tutors? } \\
\hline \multicolumn{3}{|c|}{$\begin{array}{l}\text { Yes } \\
75 \%\end{array}$} & & $\begin{array}{l}\text { No } \\
25 \%\end{array}$ \\
\hline \multicolumn{5}{|c|}{ To what degree are you satisfied with the help given by your tutors? } \\
\hline \multicolumn{2}{|c|}{$\begin{array}{l}\text { Very much } \\
\quad \mathbf{5 5 \%}\end{array}$} & $\begin{array}{l}\text { Much } \\
15 \%\end{array}$ & & $\begin{array}{l}\text { Veutral } \\
30 \%\end{array}$ \\
\hline \multicolumn{5}{|c|}{$\begin{array}{l}\text { To what extent did your tutors help you when asked for help during the } \\
\text { project period? }\end{array}$} \\
\hline \multicolumn{2}{|c|}{$\begin{array}{c}\text { Very much } \\
33 \% \\
\end{array}$} & $\begin{array}{l}\text { Much } \\
\mathbf{4 2 \%}\end{array}$ & & $\begin{array}{l}\text { Neutral } \\
\mathbf{2 5 \%}\end{array}$ \\
\hline \multicolumn{5}{|c|}{ Do you think Moodle alone was adequate to give you the necessary help? } \\
\hline \multicolumn{3}{|c|}{$\begin{array}{l}\text { Yes } \\
10 \%\end{array}$} & & $\begin{array}{l}\text { No } \\
90 \%\end{array}$ \\
\hline
\end{tabular}

The compound environment and the followed method helped you with your project.

\begin{tabular}{|c|c|c|c|c|}
\hline $\begin{array}{l}\text { Strongly agree } \\
15 \%\end{array}$ & $\begin{array}{l}\text { Agree } \\
35 \%\end{array}$ & $\begin{array}{c}\text { Neutral } \\
35 \%\end{array}$ & $\begin{array}{l}\text { Disagree } \\
10 \%\end{array}$ & $\begin{array}{l}\text { Strongly Disagree } \\
\mathbf{5 \%} \\
\end{array}$ \\
\hline \multicolumn{5}{|c|}{$\begin{array}{l}\text { How much did the compound LAMS-Moodle environment help in the direction } \\
\text { of your being given the help you wanted by your tutors? }\end{array}$} \\
\hline \multicolumn{2}{|c|}{$\begin{array}{l}\text { Very Much } \\
23 \%\end{array}$} & \multicolumn{2}{|c|}{$\begin{array}{l}\text { Much } \\
46 \%\end{array}$} & $\begin{array}{l}\text { Neutral } \\
\mathbf{3 1 \%}\end{array}$ \\
\hline \multicolumn{5}{|c|}{$\begin{array}{l}\text { Do you think projects divided into separate phases are better for your time } \\
\text { scheduling? }\end{array}$} \\
\hline \multicolumn{2}{|c|}{$\begin{array}{l}\text { Strongly agree } \\
\mathbf{3 0 \%}\end{array}$} & $\begin{array}{c}\text { Agree } \\
45 \%\end{array}$ & $\begin{array}{c}\text { Neutral } \\
15 \%\end{array}$ & $\begin{array}{c}\text { Disagree } \\
10 \%\end{array}$ \\
\hline
\end{tabular}

In the following Figure 2, you can see the possible correlations between the students' answers to the previous questions and their project grades. We interpret the degree of any correlation by both the shape and color of the graphic elements. Any variable is, of course, perfectly correlated with itself, and this is reflected as the diagonal lies on the diagonal of the graphic. Where the graphic element is a perfect circle, then there is no correlation between the variables. The colors used to shade the circles give another clue to the strength of the correlation. The intensity of the color is maximal for a perfect correlation and minimal (white) if there is no correlation. Shades of red are used for negative correlations and blue for positive correlations.

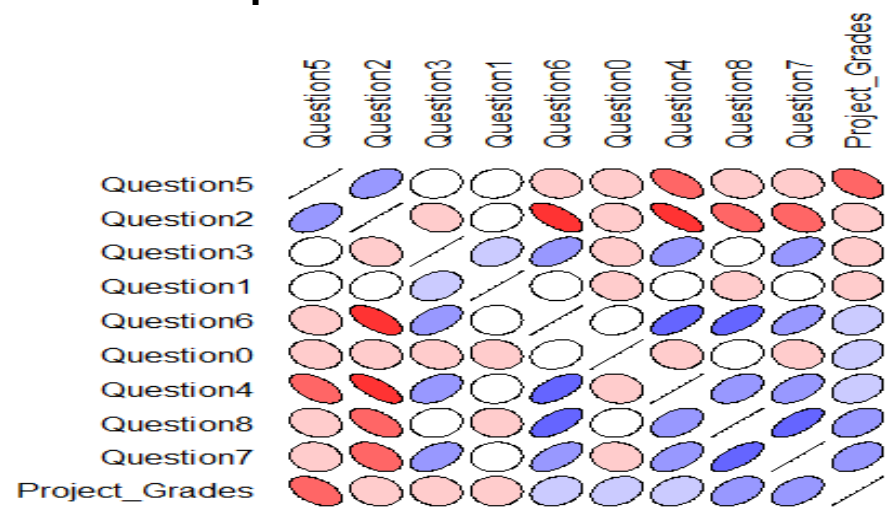

Figure 2. Statistical Analysis where you can see questions and Project Grades correlations. 
As negative points of the environment, some student mentioned: collaboration time increased because they had to collaborate strictly via the offered tools; the mind map LAMS tool had synchronization problems; the Submit Files LAMS tool had only 1MB maximum upload file size and did not allow them to delete their older submissions. Because students selected their partners on their own, some of them preferred to collaborate face-to-face, in this way bypassing the Moodle-LAMS environment.

The two tutors that were engaged in the process as supervisors wrote their remarks on this learning experience in a draft report. Their main remarks were: a) LAMS proved to be an adequate tool to apply scripted learning, which enabled them to apply the prementioned script exactly as they had designed it; b) the LAMS monitoring environment was excellent for analytically watching each student's progress and providing appropriate help when it was asked. In the following table 5, we can see the Students' and the tutors' asynchronous collaboration via the LAMS Forum tool. For example, in Group 1, Phase A, the tutor answers to 1 post by a student. The same happens in Group 1, Phase C. In Group 5, phase B, student 2 answers student 1's post, and the tutor answers student 2's post. The students with individual projects asked more times for face-to-face help than the students who worked in groups; c) the Moodle environment was suitable for giving general directions and uploading files, when tutors decided that something had to be announced to all project participants simultaneously; d) the LAMS monitoring environment needs to be enriched with an intelligent module for supervising the whole learning process.

Table 5. Student and tutors Posts in the LAMS Forum Activity.

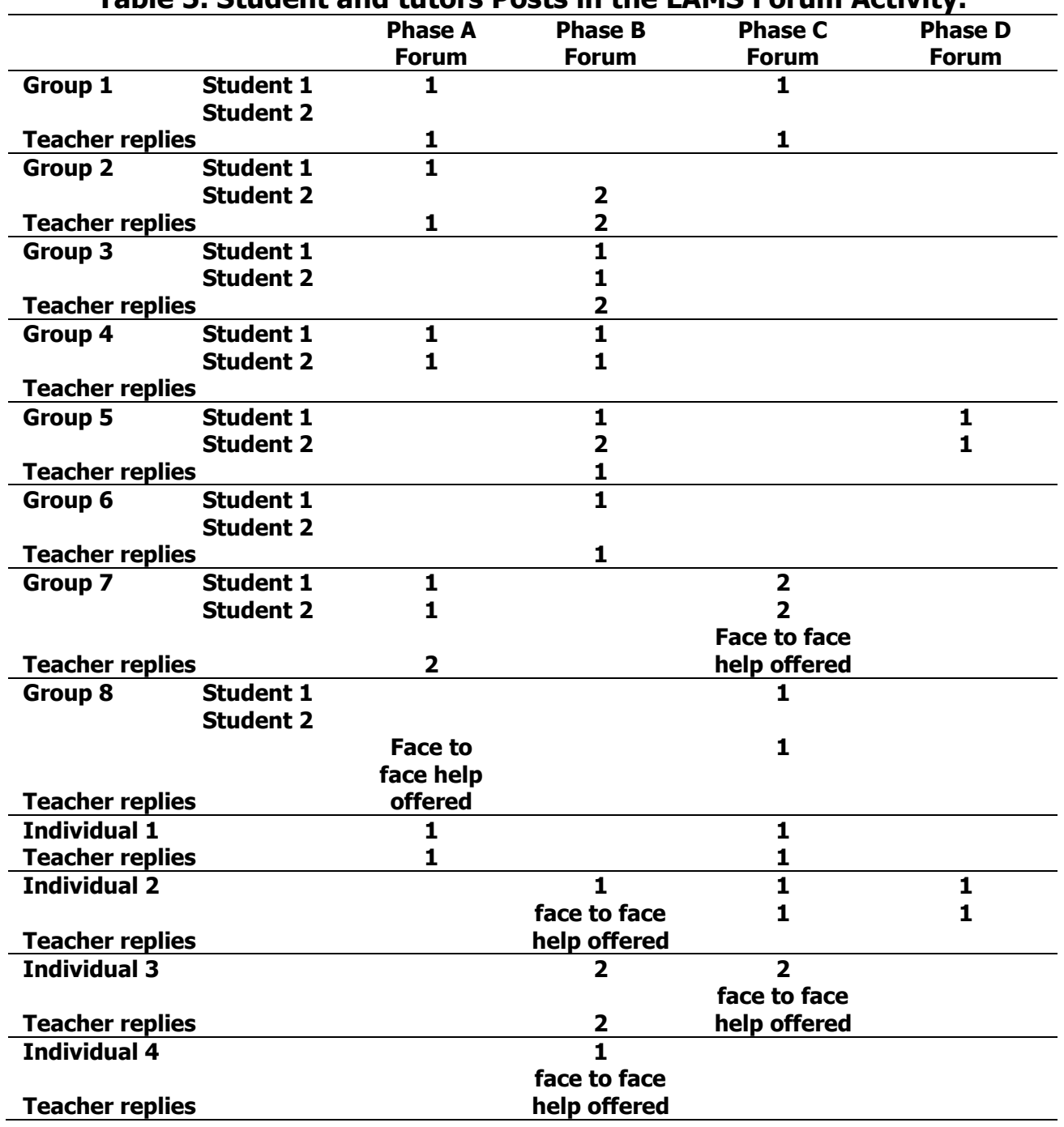




\section{DISCUSSION}

This paper has attempted to be prove the importance of combining the tools two widely used LMSs offer and the structure that a CSCL script gives, in order for: a) students to achieve a better level of collaboration and finally better final grades in the course and $b$ ) for tutors to help them as much as possible.

Learning with the use of ICTs and the abilities they offer intrinsically appeals to students, thus leading them to increase their active participation. The new stance towards learning is to be move it from a purely individual and externally programmed endeavor (i.e. planned and executed with the aid of a teacher) to learning in and with groups in a problem-based or inquiry-based situation. This is the case not only in the classroom but also in distributed environments offered via LMSs, which are used widely for a range of purposes in Tertiary Education and offer many different abilities to tutors and students alike (Alharbi \& Drew, 2014; Toland et. Al, 2014).

On the one hand, tutors need to get involved in procedures where they utilize rich media content and digital collaborative tasks, in a way that corresponds to their classroom needs and the contextual background of classroom community and offer chances of enhanced interaction. They increasingly see new information and communication technologies integrated into CSCL as useful for enhancing cognitive performance (Kirschner et al. 2014; Johnson \& Johnson 1999) and stimulating knowledge construction (Stahl, 2004). Participant tutors' opinions evolved over time as they discovered both the LMSs tools and the activity of learning design, and as they carefully consider whether the benefits of using such an environment outweigh the cost of adopting it in their courses.

On the other hand, students need to get to grips with the new era communication and collaboration tools that seem to dominate the global marketplace and reclaim their features maximally. Students in CSCL environments have reported higher levels of learning (Hertz-Lazarowitz \& Bar-Natan, 2002) and have been shown to make higher quality decisions, deliver more complete reports, participate more equally in the learning process (Fjermestad 2004; Janssen et al. 2007), and engage in more complex and challenging discussions (Jarvela et al., 2008) than when working alone. They have also reported higher levels of satisfaction compared to students in contiguous groups (Fjermestad 2004).

Qualitative and quantitative data gathered by the evaluation questionnaire at the end of the whole process indicated that both tutors and students had a positive stance towards the compound environment, which they found usable and user-friendly. The two tutors felt that the compound environment, as a web-based learning environment, fostered student interaction, team cooperation and had the potential to bring about educational change by means of student interaction and active involvement. Participant students confirmed this attitude, as could be seen from their answers.

One critical question was: "Does the compound environment offer all the necessary tools for the teaching of any course?".

Designing a general system with its materials, its examples, etc. to make it attractive for widely different teachers and subjects is not an easy task at all. Every course has its own particularities and it is practically impossible to design a general applicable environment that implements the original IMS-LD dream of "design once, deploy anywhere" (Prieto et al., 2011, 2013). Technical courses, such as Databases, in particular, need more tools than the two LMSs offer. For this reason, we used external tools such as DBDisigner, Synergo etc. In this regard, utilizing systems that deploy learning designs, regardless of the design representation (such as GLUE!-PS, see Prieto et al., 2013; Alario-Hoyos et al.,2014), might be of help. 
Other functionalities that are also mentioned quite frequently in the literature and can be added to the environment in the future are: the ability of the system to work (all or a part of it) offline, the provision of initial templates to speed up design work, tools with an accessible vocabulary, group and resource instantiation automations, simplicity of use, etc.

A frequent statement stressed by the participant students was "Why choose online interaction when we can interact by using speech in the real world of the classroom or of our homes". It was argued that the limited time of the course does not give the opportunity for extensive peer interaction, nor can it foster the students' ability to retrieve informational schema and resources. Also, without the detailed guidance that the CSCL script offers, free collaboration, with its unstructured interactions, entails the danger of the students getting lost. Of course, face-to-face interaction remains an integral and irreplaceable part of the whole learning process. Blended learning can make the most of both face-to-face and e-learning approaches, expanding the borders of today's learning process. On the other hand, there were some statements that opposed this approach, noting that students already spend too much time on chats and online discussions, where common language regulations are rather violated.

Finally, we consider that the success of the environment is obvious from the data responses to the question "Would you like to use the same compound environment with the same or another script for a given project in another course", where 15 out of 20 students and both tutors agreed.

Some limitations in our project were the following: a) the relatively low number of students who took part in the project prevents our conclusions to be statistically generalizable. But in real conditions, almost always the number of students who select an elective course isn't very big; b) the fact that the two tutors who constituted the evaluation team composed of proponents of the proposed environment (which may have introduced biases); c) despite our efforts to minimize such effects, our study still was concerned with a single intervention of limited duration (one academic semester), which lacks the validity of a more longitudinal study of usage. However, these limitations are offset by the rigorous triangulation of techniques, data sources and informants performed in the analysis. Indeed, far from pretending to have the last word said in this direction of research, we have tried to discover emerging themes to be explored in future studies.

\section{CONCLUSION AND FUTURE WORK}

In this paper, we have tried to investigate if collaboration scripts applied via a compound LMS environment helped students and their tutors to achieve better cognitive results in a Collaborative Project-Based Learning course. In order to support them during a course on 'DataBases', we designed a collaboration script, following the "Group Investigation method", and we implemented this by creating a compound e-learning collaborative environment based on two of the most popular LMSs, namely, MOODLE and LAMS. The evaluation of the students' projects, the comparison with the corresponding projects of the previous academic year and the students' opinions in the distributed evaluation questionnaire showed that the integration of the two LMSs and the followed CSCL script provided both students and their tutors with more tools and methods that were not available in each single LMS and led to a better level of collaboration and finally better final grades for the students of the course. In a future work, the LAMS-Moodle environment could be expanded with the use of a tool like Glue (see relative literature section) in order: a) to enable the easier sharing and reuse of learning designs and b) to allow teachers to widen the array of tools they can choose from to enact their learning activities, enabling them to select external tools that they (or their students) might already be familiar with (e.g. Google Documents). Also, we want to use the same compound environment with different CSCL Scripts and different group formation methods. Finally, the extended LAMS and Moodle log file analysis will help to better understand the underlying collaboration mechanisms. 


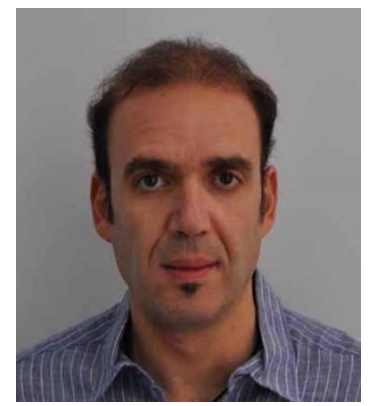

Giorgos PASCHALIS is a PhD student at the University of Patras. He holds a BSc in Electrical and Computer Engineer and a Master of Science in "Integrated Software and Hardware Systems". His research interests include Adaptive Learning Management Systems (ALMS), CSCL scripts and Collaboration Scenarios. In his PHD thesis, he engages in developing tools to support synchronous and asynchronous collaboration of small groups of students, co-present in the same classroom or at a distance. He has several publications on these topics in Greek and international conferences and journals.

\section{Giorgos PASCHALIS}

Human Computer Interaction Group,

Department of Electrical and Computer Engineering,

University of Patras, Ypatias Str., GR-26500, Rio Patras, Greece.

Phone: +30 6936706870

E-mail: gpasxali@upatras.gr

\section{REFERENCES}

Alario-Hoyos Carlos, Mupoz-Cristobal A. Juan, Prieto Luis Pablo, Bote-Lorenzo L. Miguel, Asensio-Pırez I Juan., Gomez-Sanchez Eduardo, Vega-Gorgojo Guillermo, Dimitriadis Yannis (2012). GLUE! - GLUE!-PS: An approach to deploy non-trivial collaborative learning situations that require the integration of external tools in VLEs, 1st Moodle ResearchConference, Heraklion, Crete-Greece.

Alario-Hoyos Carlos, Bote-Lorenzo L. Miguel, Gomez-Sanchez Eduardo, Asensio-Perez I. Juan, Vega-Gorgojo Guillermo, Ruiz-Calleja Adolfo. (2013). GLUE!: An architecture for the integration of external tools in Virtual Learning Environments, Computers \& Education, Volume 60, Issue 1, January 2013, Pages 122-137, ISSN 0360-1315, 10.1016/j.compedu.2012.08.010.

Alharbi, S., \& Drew, S. (2014). Using the technology assessment model in understanding academics behavioral intention to use learning management systems. International Journal of Advanced Computer Science Applications, 5(1), 143-154. doi: 10.14569/IJACSA.2014.050120

Avouris N., Kaxiras St., Koufopavlou O., Sgarbas K., Stathopoulou P. (2010). Teaching Introduction to Computing through a project-based collaborative learning approach, 14th Panhellenic Conference on Informatics, Tripoli, Greece, published by CPS.

Bower, M. (2008). A 'pedagogy-first' approach to teaching learning design. In 2008 LAMS and Learning Design Conference, Sydney, Australia, 5th December (pp. 35-42): LAMS Foundation.

Bower, M., \& Wittmann, M. (2009). Pre-service teachers' perceptions of LAMS and Moodle as learning design technologies. In Proceedings of the 4th International LAMS and Learning Design Conference, Sydney, Australia, (pp. 28 -39)

Cameron, L. (2006). Picture this: My Lesson. How LAMS is being used with pre-service teachers to develop effective classroom activities. In First International LAMS Conference 2006: Designing the Future of Learning, Sydney, (pp. 25-34): LAMS Foundation. 
Cameron, L. (2007). Using LAMS to facilitate an effective program of ICT instruction. In 2007 European LAMS Conference: Designing the future of learning, Greenwich, 5 July (pp. 39-49): LAMS Foundation.

Conole, G. (2008). The role of mediating artifacts in Learning Design. In L. Lockyer, $S$. Bennett, S. Angostinho, \& B. Harper (Eds.), Handbook of Research on Learning Design and Learning Objects: Issues, Applications and Technologies (pp. 187207). IGI Global Publishing.

Dillenbourg, P., \& Schneider, D. (1995). Collaborative learning and the internet. Available: http://tecfa.unige.ch/tecfa/research/CMC/colla/iccai95_1.html

Dillenbourg, P., Baker, M., Blaye, A., O'Malley, C. (1995). The evolution of research on collaborative learning. In: Spada, E., Reiman, P. (eds.) Learning Human and Machine: Towards an interdisciplinary learning science, pp. 189-211. Elsevier, Oxford.

Dillenbourg, P. (2002). Over-scripting CSCL: The risks of blending collaborative learning with instructional design. In P. A. Kirschner (Ed.), Three worlds of CSCL Can we support CSCL (pp. 61-91). Heerlen: Open Universiteit Nederland.

Dillenbourg, P., \& Jermann, P. (2007). Designing integrative scripts.

Donnelly, R. and Fitzmaurice, M. (2005). Collaborative project-based learning and problem-based learning in higher education: A consideration of tutor and student roles in learner-focused strategies. In O'Neill, G., Moore, S., McMullin, B. (eds): Emerging Issues in the Practice of University Learning and Teaching. Dublin: AISHE.

Dougiamas, M. and Taylor, P.C.: Moodle. (2003). Using Learning Communities to Create an Open Source Course Management System. Proceedings of the EDMEDIA 2003 Conference, Honolulu, Hawaii.

Fischer, F., Kollar, I., Mandl, H., \& Haake, J. (2007). Scripting computer-supported collaborative learning. Cognitive, computational, and educational perspectives. New York: Springer.

Fjermestad, J. (2004). An analysis of communication mode in group support systems research. Decision Support Systems, 37, 239-263.

Ghiglione, E., Rodríguez Aliberas, M., Vicent, L., \& Dalziel, J. (2009). Using Moodle Activities within LAMS. Paper presented at the 2009 European LAMS Conference. 6-9 July, Milton Keynes.

Gillham B. (2000). Developing a questionnaire (real world research). London: Continuum.

Hake, R. (1998). Interactive-Engagement versus Traditional Methods: A Six-ThousandStudent Survey of Mechanics. Test Data for Introductory Physics Courses. Am. J. Phys., 66(1), 64-74.

Hernandez-Leo, D., Villasclaras-Fernandez, E. D., Jorrín-Abellan, I. M., Asensio-Perez, J. I., Dimitriadis, Y., Ruiz-Requies, I. (2006). COLLAGE, a collaborative learning design editor based on patterns. Educational Technology and Society, 9(1), 58-7.

Hertz-Lazarowitz, R. \& Miller, N. (1992). Interaction in Cooperative Groups: The Theoretical Anatomy of Group Learning. New York and London: Cambridge University Press, 294pp. 
Hertz-Lazarowitz, R., \& Bar-Natan, I. (2002). Writing development of Arab and Jewish students using cooperative learning $(\mathrm{CL})$ and computer-mediated communication (CMC). Computers \& Education, 39, 19-36.

Janssen, J., Erkens, G., Kanselaar, G., \& Jaspers, J. (2007). Visualization of participation: Does it contribute tosuccessful computer-supported collaborative learning. Computers \& Education, 49, 1037-1065.

Jarvela, S., Jarvenoja, H., \& Veermans, M. (2008a). Understanding dynamics of motivation in socially shared learning. International Journal of Educational Research, 47(1), 122-135.

Jarvela , S., Kirschner, P. A., Panadero, E., Malmberg, J., Phielix, C., Jaspers, J., Koivuniemi, M., Jarvenoja, H. (2015). Enhancing socially shared regulation in collaborative learning groups: designing for CSCL regulation tools. Educational Technology Research and Development, 63, 125-142. doi: 10.1007/s11423-0149358-1

Joint Information Systems Committee (2007). Authoring using Learning Design (ALeD) Project Final Report.

Johnson, D.W., Johnson, R.T., \& Smith, K.A. (1998). Cooperative learning returns to college: What evidence is there that it works? Change, 30 (4), 26-35.

Johnson, D. W., \& Johnson, R. T. (1999). Learning together and alone: Cooperative, competitive, and individualistic learning (5th ed.). Boston, MA: Allyn and Bacon.

Kearney, M., \& Cameron, L. (2008). Students as designers. Paper presented at the 2008 LAMS and Learning Design Conference, 5th December, Sydney.

Kirschner, P. A., Kirschner, F., \& Janssen, J. (2014). The collaboration principle in multimedia learning. In R. Mayer (Ed.), The Cambridge handbook of multimedia learning (2nd ed., pp. 547-575). New York: Cambridge University Press.

Kollar, I., Fischer, F., Slotta, J.D. (2005). Internal and external collaboration scripts in web based science learning at schools. In: Koschmann, T., Suthers, D., Chan, T.W. (eds.) Computer supported collaborative learning 2005: The next 10 Years, pp. 331-340. Lawrence Erlbaum, Mahwah.

LAMS International (2009). LAMS: Learning Activity Management System home page, Retrieved 29th August, 2009, from http://www.lamsinternational.com/

Masterman, E., Jameson, J., \& Walker, S. (2009). Capturing teachers' experience of learning designthrough case studies. Distance Education, 30(2), 223-238.

Mor, Y., \& Mogilevsky, O. (2013). The learning design studio: collaborative design inquiry as teachers' professional development. Research in Learning Technology, 21.

O'Donnell, A.M., Dansereau, D.F.(1992). Scripted cooperation in student dyads: A method for analyzing and enhancing academic learning and performance. In: HertzLazarowitz, R., Miller, N. (eds.) Interaction in cooperative groups: The theoretical anatomy of group learning, pp. 120-141. Cambridge University Press, London.

Oppenheim An. (1992). Questionnaire design, interviewing and attitude measurement. London: Continuum. 
Prieto, L. P., Asensio-Perez, J. I., Dimitriadis, Y., Gomez-Sanchez, E., \& Muňoz Cristobal, J. A. (2011). GLUE!-PS: A multi-language architecture and data model to deploy TEL designs to multiple learning environments. In Proceedings of the European Conference on Technology-Enhanced Learning (EC-TEL 2011) (pp. 285-298).

Prieto, L. P., Asensio- Perez, J. I., Munoz Cristobal, J. A., Dimitriadis, Y., Jorrín-Abellan, I. M., \& Gomez-Sanchez, E. (2013). Enabling teachers to deploy CSCL designs across Distributed Learning Environments. IEEE Transactions on Learning Technologies, 6, 324-336.

DOI: http://doi.ieeecomputersociety.org/10.1109/TLT.2013.22.

Prieto L. P., Tchounikine P., Asensio-Perez J. I., Sobreira P., Dimitriadis Y. (2014). Exploring teachers' perceptions on different CSCL script editing tools, Computers \& Education, 78, pp. 383-396

Rummel, N., Spada, H. (2007). Can people learn computer-mediated collaboration by following a script? In: Fischer, F., Kollar, I., Mandl, H., Haake, J. (eds.) Scripting computer supported collaborative learning: Cognitive, computational and educational perspectives, pp. 39-55. Springer, New York).

Sapsford R. (1999). Survey research. London: Sage.

Savery, J.R. (2015). Overview of problem-based learning: Definitions and distinctions, In Walker A., Leary H., Hmelo-Silver C., Ertmer P. (Eds), Essential Readings in Problem -Based Learning (pp 5-17), Print ISBN:978-1-55753-682-2, Purdue University Press.

Sharan S. (1980). Cooperative learning in groups: Recent methods and effects on achievement, attitudes, and ethnic relations. Review of Educational Research, 50:241-272.

Sharan, S., \& Hertz-Lazarowitz, R.(1980). A group investigation method of cooperative learning in the classroom. In S. Sharan et al. (Eds.), Cooperation in education. Provo, UT: Brigham Young University Press, pp. 14-46.

Sharan, Y., \& Sharan, S. (1994). Group Investigation in the cooperative classroom. In S. Sharan (Ed.), Handbook of cooperative learning. Westport: Greenwood Press, pp. 97-114.

Stahl, G. (2004). Groupware goes to school: Adapting BSCW to the classroom. International Journal of Computer Applications in Technology, 19(3/4), 1-13.

Talavera L. and Gaudioso E. (2004). Mining Student Data To Characterize Similar Behavior Groups In Unstructured Collaboration Spaces, In Workshop in artificial intelligence in CSCL, 16th European conference on artificial intelligence, pp 1723.

Tan Geok-Chin Ivy, Sharan S., and Lee Kim-Eng C. (2006). Group Investigation and Student Learning: An Experiment in Singapore Schools. Marshall Cavendish Academic.

Thompson, N., McGill, T., (2014), The Application of Affective Computing Technology to ELearning, In: Pedagogical Considerations and Opportunities for Teaching and Learning on the Web, IGI Global, pages to 109. 
Toland, S., White, J., Mills, D., \& Bolliger, D. U. (2014). EFL instructors perceptions of usefulness and ease of use of the LMS Manaba. The JALT CALL Journal, 10(3), 221-236.

Voyiatzaki E. and Avouris N. (2010). Teaching Algorithms using a collaborative learning environment: Studies and findings, 5th Hellenic Conference of Didactics of Informatics, Athens, April 2010, 91-100. (in Greek), available from http://hci.ece.upatras.gr/

Walker, S., \& Masterman, L. (2006). Learning designs and the development of study skills: Reuse and community perspectives. In Proceedings of the First International LAMS Conference 2006: Designing the Future of Learning, Sydney, Australia, 6-8 December (pp. 89-98): LAMS Foundation.

Walvoord, B. F. (1986). Helping Students Write Well: A Guide for Teachers in AII Disciplines. (2nd ed.), New York: Modern Language Association.

Weinberger, A., Fischer, F., Mandl, H. (2002). Fostering computer supported collaborative learning with cooperation scripts and scaffolds. In: Stahl, G. (ed.) Computer Support for Collaborative Learning: Foundations for a CSCL Community. Proceedings of the Conference on Computer Support for Collaborative Learning, pp. 573-574. Erlbaum, Hillsdale. 